\title{
Using electroretinograms and multi-model inference to identify spectral classes of photoreceptors and relative opsin expression levels
}

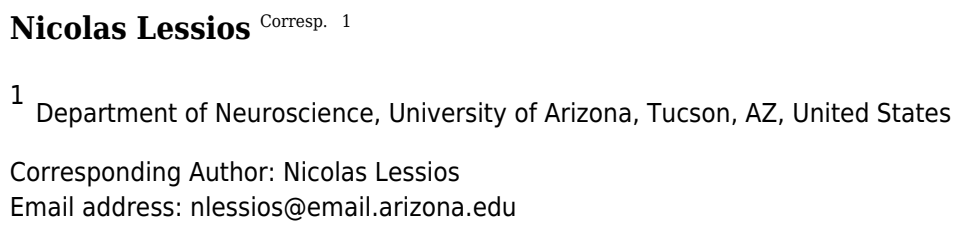

Understanding how individual photoreceptor cells factor in the spectral sensitivity of a visual system is essential to explain how they contribute to the visual ecology of the animal in question. Existing methods that model the absorbance of visual pigments use templates which correspond closely to data from thin cross-sections of photoreceptor cells. However, few modeling approaches use a single framework to incorporate physical parameters of real photoreceptors, which can be fused, and can form vertical tiers. Akaike's Information Criterion (AIC) was used here to select absorptance models of multiple classes of photoreceptor cells that maximize information, given visual system spectral sensitivity data obtained using extracellular electroretinograms and structural parameters obtained by histological methods. This framework was first used to select among alternative hypotheses of photoreceptor number. It identified spectral classes from a range of dark-adapted visual systems which have between one and four spectral photoreceptor classes. These were the velvet worm, Principapillatus hitoyensis, the branchiopod water flea, Daphnia magna, normal humans, and humans with enhanced Scone syndrome, a condition in which S-cone frequency is increased due to mutations in a transcription factor that controls photoreceptor expression. Data from the Asian swallowtail, Papilio xuthus, which has at least five main spectral photoreceptor classes in its compound eyes, were included to illustrate potential effects of model oversimplification on multi-model inference. The multi-model framework was then used with parameters of spectral photoreceptor classes and the structural photoreceptor array kept constant. The goal was to map relative opsin expression to visual pigment concentration. It identified relative opsin expression differences for two populations of the bluefin killifish, Lucania goodei. The modeling approach presented here will be useful in selecting the most likely alternative hypotheses of opsin-based spectral photoreceptor classes, using relative opsin expression and extracellular electroretinography. 
1

2

3

4

5

6

7

8

9

10

11

12

13

14

15

16

17

18

19

20

21

22

23

24

25

26

27

28

29

30

31

9

1

Using electroretinograms and multi-model inference to identify spectral classes of photoreceptors and relative opsin expression levels

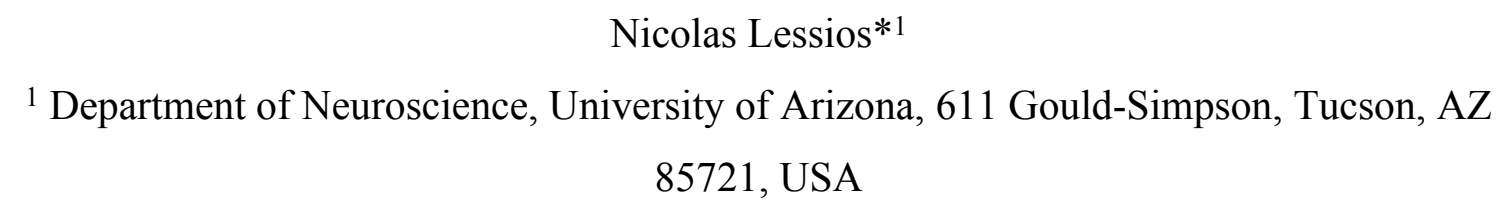

*Corresponding author: nlessios@email.arizona.edu

(1)

2

3

4

15

6

17

(8)

0




\begin{abstract}
Understanding how individual photoreceptor cells factor in the spectral sensitivity of a visual system is essential to explain how they contribute to the visual ecology of the animal in question. Existing methods that model the absorption of visual pigments use templates which correspond closely to data from thin cross-sections of photoreceptor cells. However, few modeling approaches use a single framework to incorporate physical parameters of real photoreceptors, which can be fused, and can form vertical tiers. Akaike's Information Criterion (AIC) was used here to select absorptance models of multiple classes of photoreceptor cells that maximize information, given visual system spectral sensitivity data obtained using extracellular electroretinograms and structural parameters obtained by histological methods. This framework was first used to select among alternative hypotheses of photoreceptor number. It identified spectral classes from a range of dark-adapted visual systems which have between one and four spectral photoreceptor classes. These were the velvet worm, Principapillatus hitoyensis, the branchiopod water flea, Daphnia magna, normal humans, and humans with enhanced S-cone syndrome, a condition in which S-cone frequency is increased due to mutations in a transcription factor that controls photoreceptor expression. Data from the Asian swallowtail, Papilio xuthus, which has at least five main spectral photoreceptor classes in its compound eyes, were included to illustrate potential effects of model oversimplification on multi-model inference. The multimodel framework was then used with parameters of spectral photoreceptor classes and the structural photoreceptor array kept constant. The goal was to map relative opsin expression to visual pigment concentration. The framework identified relative opsin expression differences for two populations of the bluefin killifish, Lucania goodei. The modeling approach presented here will be useful in selecting the most likely alternative hypotheses of opsin-based spectral photoreceptor classes, using relative opsin expression and extracellular electroretinography.
\end{abstract}




\section{INTRODUCTION}

Animals possess a diversity of opsin proteins, one of the main genetic components underlying spectral photoreceptor classes (Porter et al., 2012). It is now possible to identify functional amino acid sequence sites of opsin proteins that determine the spectral sensitivity of photoreceptors (Arendt et al., 2004; Porter et al., 2007). The number and wavelength sensitivity of spectral photoreceptor classes an organism possesses is needed to understand whether it can discriminate natural spectra (i.e has some form of color vision), and also to understand the mechanistic context of visually-guided behavior (Kelber \& Osorio, 2010). Spectral classes of photoreceptors are generally identified using a combination of extracellular and intracellular electroretinographic (ERG) techniques (Arikawa, Inokuma \& Eguchi, 1987). Extracellular recordings detect a summed contribution of multiple classes of photoreceptors, including relatively rare classes that are difficult to identify using intracellular techniques. It is possible to isolate spectral photoreceptor classes using chromatic adaptation, where light of a restricted waveband is used to light-adapt single photoreceptor classes and the resulting effects on spectral sensitivity are observed in extracellular recordings. However, because visual pigments are all natively sensitive to short wavelengths (Bowmaker, 1999), this procedure is most applicable to long wavelength receptors in organisms that possess up to three spectral photoreceptor classes (Goldsmith, 1986). Intracellular techniques are the most accurate for verifying the existence of spectral classes; but they can be further supported by modeling approaches which incorporate physical parameters obtained from histological techniques (Stavenga \& Arikawa, 2011).

I have developed a framework of multi-model selection using overall spectral sensitivities of the visual system. The goals of this framework were to:

A. Identify the most likely number of opsin-based spectral photoreceptor classes of visual systems from extracellular ERGs, and from known parameters of the photoreceptor array;

B. Establish whether differences between individuals in structural photoreceptor parameters affect identification of the same underlying number of opsin-based spectral photoreceptor classes found in A.

C. Map relative opsin expression levels to relative visual pigment concentrations when structural parameters and opsin identities of the photoreceptor array are known. 
The framework used here employs Akaike's information Criterion $\left(\mathrm{AIC}_{\mathrm{c}}\right)$ to select among competing alternative hypotheses (Akaike, 1974). AIC is an objective measure that imposes a realistic penalty for over-parameterization (Burnham \& Anderson, 2002). For goals A) and B) the alternative hypotheses are the number and relative area in cross section, or frequency, of spectral photoreceptor classes. For goal C), the alternative hypotheses are the number of opsins which differ in relative expression level. Others have used multi-model selection to identify the number of photoreceptors in the eyes of oceanic fish, using the relative contributions of photoreceptor classes in cross-section to absorbance (Horodysky et al., 2008, 2010). Existing models of absorptance, which use parameters of real photoreceptors (Snyder, Menzel \& Laughlin, 1973) are developed here to incorporate parameters of multiple tiers, or to model absorptive layers affecting the spectral sensitivity of underlying photoreceptors.

\section{MATERIALS AND METHODS}

\section{Visual modeling of photoreceptor absorptance}

The fused photoreceptor array per unit length was modeled as

$$
\xi_{j}(\lambda)=\sum \alpha_{i}(\lambda) \frac{A_{i}}{A} k,
$$

where $\alpha_{i}$ is the normalized absorption spectrum of each rhodopsin visual pigment, $A i / A$ is the relative area or frequency in cross section of each photoreceptor $i$, and $k$ is the peak absorption coefficient. Values used for $k$ for invertebrates $\left(0.008 \mu \mathrm{m}^{-1}\right)$ were established by (Bruno, Barnes \& Goldsmith, 1977) and are typical for crustaceans and insects (Cronin et al., 2014). Values used for $k$ for humans $\left(0.015 \mu \mathrm{m}^{-1}\right)$ are typical for vertebrates (Wyszecki \& Stiles, 1982). Absorptance of a tiered photoreceptor array, composed of $j$ tiers was calculated as follows,

$$
S(\lambda)=\sum\left(T_{(j-1)}\left(1-e^{-\xi_{j}(\lambda) l_{j}}\right)\right)
$$

Where $T_{j-1}$ is the transmittance through all preceding vertical tiers ( $T_{0}=1.0$ for the first tier). Normalized absorbance templates developed by Stavenga, Smits \& Hoenders (1993), referred to here as SSH, and by Govardovskii et al. (2000), referred to here as GFKRD, were used for visual pigment absorption spectra $\alpha_{i}$ each of which has a wavelength of peak absorbance $\lambda_{\max }$.

4 Normalized absorption templates have two primary components, an alpha band with a wavelength of peak absorbance that is determined by the interaction between the chromophore 
116

117

118

119

120

121

122

123

124

125

126

127

128

129

130

131

132

133

134

135

136

137

138

139

140

141

142

143

144

145

146

and the opsin protein, and a beta band which absorbs in the UV, and is mainly determined by the chromophore itself (Bowmaker, 1999). Effects of including both alpha and beta bands were assessed in a preliminary analysis of a global model, then only alpha bands were considered (see $\mathrm{AIC}_{\mathrm{c}}$ procedure). $S(\lambda)$ was normalized to 1 as in (Stavenga \& Arikawa, 2011).

\section{Example selection:}

I used organisms which have between one and five classes of spectral photoreceptors to examine capabilities and limitations of the described framework. Four organisms were used to address goals A) and B), and spectral sensitivities from dark-adapted eyes were used to minimize effects of variation among individuals of changing visual pigment concentration, pigment migration, or varying levels of metarhodopsin (Stavenga, 2010). The fifth organism was used to address goal C) to map differences in visual pigment concentrations to relative opsin expression level for two populations of the same species.

1) The onycophoran velvet worm, Principapillatus hitoyensis (Figure 1A) expresses a single spectral opsin class in its photoreceptors (Beckmann et al., 2015).

2) Homo sapiens possesses one rod and three cone (S, M, L) photoreceptor classes. Normal human scotopic sensitivity (Figure 1B), is represented by S-class cone and rod photoreceptor sensitivities (Bowmaker \& Dartnall, 1980; Wyszecki \& Stiles, 2000). In contrast, scotopic sensitivity of patients with enhanced S-cone syndrome (Figure 1C) is a condition in which S-cone frequency is increased due to mutations in a transcription factor that controls photoreceptor expression (Haider et al., 2000). Human absorptance models are corrected here for transmittance through the lens and a distal macula tier protecting the retina that affects spectral sensitivity (Wyszecki \& Stiles, 1982).

3) The branchiopod crustacean water flea, Daphnia magna (Figure 1D) possesses four spectral photoreceptor classes (Smith \& Macagno, 1990).

4) The swallow-tail butterfly, Papilio xuthus (Figure 1E, F) possesses at least five main spectral classes of photoreceptor type (Arikawa, Inokuma \& Eguchi, 1987), in several classes of ommatidia with specialized filtering pigments (Stavenga \& Arikawa, 2011).

5) The bluefin killifish, Lucania goodei, possesses five cone photoreceptor classes based on known opsins (SWS1, SWS2B, SWS2A, RH2-1, and LWS). Separate populations of this species have been shown to regulate opsin expression depending on their photic 
environments (Fuller et al., 2004). Killifish absorptance models are corrected here for transmittance through a tier of distal ellipsosomes associated with cone classes found in the related killifish Fundulus heteroclitus (Flamarique \& Harosi, 2000), and through the lens of the Nile tilapia Oreochromis niloticus (Lisney, Studd \& Hawryshyn, 2010). The relative frequency of the cones cone classes that express SWS2B, RH2-1, and LWS were corrected to take into account that they are double cones.

\section{Data Extraction, binning, and averaging from multiple recording locations:}

Published spectral sensitivity data were extracted using GetData v.2.26 (Fedorov, 2013) from (Arikawa, Inokuma \& Eguchi, 1987; Smith \& Macagno, 1990; Jacobson et al., 1990; Fuller et al., 2003; Beckmann et al., 2015). Where needed, units were converted from log sensitivity to relative sensitivity. Preliminary analysis indicated that $20 \mathrm{~nm}$ and $10 \mathrm{~nm}$ wavelength intervals provided identical results. Binning was therefore carried out at $20 \mathrm{~nm}$ intervals for all sensitivity data. Sensitivity ranges were $410-690 \mathrm{~nm}$ for humans, $350-690 \mathrm{~nm}$ for $P$. hitoyensis and $D$. magna and 310-690 nm for P. xuthus. For P. xuthus (Arikawa, Inokuma \& Eguchi, 1987) had recorded extracellularly from multiple regions of the compound eye (dorsal, medial, and ventral). Binned sensitivities from each region were therefore averaged to provide a single relative spectral sensitivity (Figure 1E and F).

\section{Incorporating known photoreceptor lengths $l_{j}$ in Eq. [2]:}

Photoreceptor lengths were estimated or taken from published sources: P. hitoyensis $(100 \mu \mathrm{m})$ (Beckmann et al., 2015); H. sapiens parafovea (22.5 $\mu \mathrm{m}$ ) (Bowmaker \& Dartnall, 1980; Cronin et al., 2014); Daphnia magna $(12.0 \mu \mathrm{m})$ (Smith \& Macagno, 1990); Papilio xuthus $(500 \mu \mathrm{m})$ (Arikawa \& Stavenga, 1997); Lucania goodei (18 $\mu \mathrm{m}$ ) (Moldstad, 2008). The fused crosssectional and tiered three-dimensional photoreceptor array is known for D. magna and for P. xuthus: as in many insects and crustaceans (Kelber \& Henze, 2013), the shortest wavelength receptor of both species becomes axon-like partway through the optical unit. Models considered here for D. magna and P. xuthus which have more than one spectral class of photoreceptor incorporate this structure in Eq. [2], and in the optimization procedure. The shortest wavelength receptor of D. magna ommatidia forms a fused structure in the distal (upper) half of the optical unit $(6.0 \mu \mathrm{m})$, with a short-wavelength receptor replaced by a longer-wavelength sensitive receptor in the proximal (lower) half of the optical unit (6.0 um). The distal two-thirds of the 
177 optical unit $(333 \mu \mathrm{m})$ of $P$. xuthus ommatidia are modeled as a single optical unit, replaced by a

178 long wavelength receptor in the proximal portion $(167 \mu \mathrm{m})$.

179

Parameter estimates, maximum likelihood estimation, optimization, and $\mathrm{AIC}_{\mathrm{c}}$ procedure

182

183

184

185

The maximum likelihood estimate (MLE) of each model was calculated according to (Burnham \& Anderson, 2002),

$$
\log (L(\underline{\hat{\Theta}}))=-\frac{1}{2} \log \left(\hat{\sigma}^{2}\right)-\frac{n}{2} \log (2 \pi)-\frac{n}{2}
$$

where the MLE for $\hat{\sigma}^{2}$ is $\frac{R S S}{n}$, and RSS is the residual sum of squares for a given model. Optimization of model parameters $\lambda_{\max }$, and $A i / A$ for goals A) and B), then $k$ for goal C) were carried out using custom scripts, and the Optimization Toolbox in MATLAB. A linear constraint was used for D. magna and P. xuthus during optimization to maintain $\lambda_{\max 1}$ as the shortest wavelength receptor in the first tier $\left(\lambda_{\max }<<\lambda_{\max i+1}\right)$. The absorption coefficients for Lucania goode $i$ were constrained to a value greater than $0.001 / \mu \mathrm{m}$ and less than $1.000 / \mu \mathrm{m}$.

I used Akaike's information criterion for small samples $\left(\mathrm{AIC}_{\mathrm{c}}\right)$ to compare the optimized log-likelihood,

$$
A I C_{c}=-2 \log \left(L(\underline{\hat{\Theta}})+\frac{2 K(K+1)}{n-K-1}\right),
$$

where $K$ is the number of parameters.

AIC scores were compared to the best model $\left(\triangle A I C_{c}=A I C-\min A I C\right)$, and were weighted using Akaike weights,

$$
{ } A I C_{C}=e^{-0.5 \Delta A I C_{i}} /\left(\sum_{1}^{R} e^{-0.5 \Delta A I C} r\right),
$$

where $R$ is the number of models considered. $w A I C_{C}$ provides a weighting indicating the likelihood of a single optimized model compared to all considered models, while penalizing for over-parameterization. Akaike weights were used to calculate evidence ratios relative to the best model (Tables 1,2 and S1,S2). See (Posada \& Buckley, 2004; Symonds \& Moussalli, 2011) for abbreviated explanations of Akaike weights and evidence ratios.

The above procedure was first used to optimize models to extracellular ERG data for $D$. magna. Beta bands were considered for every possible photoreceptor, an "all subsets" generalized linear model examining the influence of each parameter on $S(\lambda)$ relative to known 
$206 S(\lambda)$, comparing among 124 optimized models (Table S4). Generalized linear model results

207 indicated beta bands were uninformative for model selection as they were the least important

208 covariate $\beta$, in this case $\left(\frac{\widehat{\beta_{\beta}}}{E(y i)}\right)<3.0$, and upon removal led to a reduction in $\mathrm{AIC}_{\mathrm{c}}$ according to

209 methods outlined in (Burnham \& Anderson, 2002; Arnold, 2010). Models which included beta

210 bands were therefore removed and only models in Tables S1, S2 and S3 were included for the

211 formal analysis. wavelength of peak absorbance for visual pigments. The reason is the absorbance of visual pigments can be predicted very accurately once the wavelength of peak absorbance, $\lambda_{\max }$, is identified. In practice, this is achieved by excising a portion of the retina, taking sections of the photoreceptors, and measuring the fraction of light which is transmitted or absorbed. Ideally, this is performed on single photoreceptors, using a range of narrow-bandwidth light to infer the wavelength of peak absorbance. Vision researchers found that peak absorbance can be used to normalize the rest of the absorbance curve to create a template curve (Dartnall, 1953). Then, using just the wavelength of peak absorbance, it was found the rest of the curve can be predicted using mathematical expressions. These nomograms correspond closely to visual pigment that is extracted in solution (Govardovskii et al., 2000). Therefore, the idea of a "universal visual pigment template" is very useful when the wavelength of peak absorbance is known, referred to as "normalized absorption templates". And because $\lambda_{\max }$ of a visual pigment is primarily determined by the particular opsin amino acids in opsin-chromophore interactions, it is now possible to specify which amino acids determine a specific absorbance profile (Arendt et al., 2004; Porter et al., 2007). However, a normalized absorption template can be misleading when placing the function of a single photoreceptor class in context of other photoreceptors, or the overall spectral sensitivity of the eye. Therefore, absorptance models were used here with the assumption that they are a more realistic approximation for overall sensitivity estimated from extracellular ERGs, and in order to incorporate multiple layers of filtering. be used to identify the most likely number of underlying spectral classes of photoreceptors. As can be seen from the fit of each best model to the data (Figure 1), and from the evidence ratios 
237 (Tables 1 and 2), the framework described here is generally able to resolve the number and 238 relative cross sectional area or frequency of the photoreceptors in the visual systems I have modeled. It is important to note that AIC avoids over-parameterization with the clearest example shown here for velvet worm Principapillatus hitoyensis. Though one to five spectral classes were considered (Table 1 and S1), in order to add parameters (i.e. more complex models), the likelihood of those models, given the data, must outweigh the penalty imposed by additional parameters. $P$. hitoyensis sensitivity (Figure 1A, points) is represented by a single spectral opsin class expressed in its photoreceptors with an estimated $\lambda_{\max }$ of $484 \mathrm{~nm}$, and the best-supported model here was a single receptor GFKRD absorptance model with $\lambda_{\max }$ of $481 \mathrm{~nm}$ (Figure 1A, black curve).

This framework is also able to resolve the presence of more photoreceptors, if the data support them. Daphnia magna sensitivity (Figure 1D) is represented by four spectral photoreceptor classes with a distal UV receptor (Smith \& Macagno, 1990), and the bestsupported model here was a four receptor SSH absorptance model (Table 2, and S2). The results strongly support the presence of a UV sensitive photoreceptor in the compound eye of D. magna. Though it was poorly supported in comparison to the best model (evidence ratio $>2.0$ ), the second best-supported model for D. magna is a three receptor SSH model, rather than a four receptor GFKRD model (Table 2). This finding can be explained by better performance of the SSH template in the UV range, which has been documented (Stavenga, 2010). Future modeling efforts for organisms with UV photoreceptors should expect stronger cumulative performance of absorptance models based on the SSH template.

Results for $P$. hitoyensis and D. magna indicate this technique resolves a range of opsinbased photoreceptor classes in visual systems. In comparison to more traditional null-hypothesis testing (Table 3), AIC results were similar, with the exception of humans, in which an $F$-test of nonlinear regression results would identify 3 spectral photoreceptor classes. Table 3 also shows how the penalty imposed by AIC for unneeded parameters provides similar results to comparisons of non-linear regression models. Intuitively, this type of multi-model selection should make sense in terms of natural selection, as maintaining photoreceptors is costly, and if those do not match natural spectra, there is an inarguable cost. It should also be emphasized that, to date, $P$. hitoyensis and D. magna have not been found to possess specialized optical filtering in their visual systems (Smith \& Macagno, 1990; Martin, 1992; Beckmann et al., 2015). 
To establish whether this framework can identify the same number and photoreceptor $\lambda_{\max }$ of a visual system when the frequency of the spectral photoreceptor classes is known to change, this framework was applied to scotopic human spectral sensitivities. Normal and Enhanced S cone Human scotopic sensitivities (Figure 1B and 1C) are represented by S cone and rod photoreceptors, with a higher frequency of S cones in patients with Enhanced S Cone syndrome (Jacobson et al., 1990; Hood et al., 1995; Haider et al., 2000). Although the full width half-maximum (FWHM) of normal, dark-adapted humans is $20 \mathrm{~nm}$ narrower than $P$. hitoyensis (Figure 1), the best-supported model using this technique is a two receptor GFKRD absorptance model (Table 1). The narrow bandwidth of normal dark-adapted humans can be explained primarily by the presence of the macula, and illustrates that overlooking absorptive layers which affect spectral sensitivity of underlying photoreceptors leads to erroneous interpretation of the number of spectral photoreceptor classes they possess. As can be seen from Table 1 and Figure 1, the framework presented here identifies increased frequency of S cones in individuals with Enhanced S Cone syndrome, and also identifies two primary spectral photoreceptor classes. xuthus sensitivity (Figure 1E and F). Absorptance models (Figure 1E, dashed lines) illustrate poor results with this technique for $P$. xuthus: as can be seen by the very broad $(>100 \mu \mathrm{m}$ at FWHM) sensitivity of each modeled photoreceptor in the "best" model, self-screening has been over-estimated. P. xuthus is known to employ specialized filtering pigments in part to sharpen the spectral sensitivity of its receptors (Arikawa, 2003). Opsins are expressed heterogeneously in separate classes of ommatidia leading to regions of their compound eyes differing in spectral sensitivity (Arikawa, Inokuma \& Eguchi, 1987; Arikawa \& Stavenga, 1997). However, absorbance (Figure 1F) at cross-section two thirds from the distal tip of the rhabdom of an ommatidium selects a five spectral photoreceptor GFKRD absorbance model. P. xuthus possess filtering pigments in the peak spectral regions of the photoreceptor classes with the largest deviations identified by this technique $\left(\lambda_{\max 1}, \lambda_{\max 2} \lambda_{\max 5}\right.$, Table 2$)$. P. xuthus is not known to possess filtering pigments in the peak bandwidths of the remaining spectral classes $\left(\lambda_{\max 3}, \lambda_{\max 4}\right.$, Table 2) (Wakakuwa, Stavenga \& Arikawa, 2007). The comparison of P. xuthus absorbance and absorptance results serve to illustrate that multi-model selection must be employed judiciously based on what is known for a given visual system. Absorbance results presented here fail to identify the diversity of receptors, and ommatidial spectral classes of organisms where fine-scale 
299

300

301

302

303

304

305

306

307

308

309

310

311

312

313

314

315

316

317

318

319

320

321

322

323

324

325

326

327

328

329

spectral discrimination is essential to their visual ecology (Koshitaka et al., 2008). The modeling framework is still useful for incorporating both electrophysiology and histology to compare the effects on overall spectral sensitivity. Deviations from these models can identify the presence of previously unknown spectral filters for an organism, or can provide objective multi-model inference to validate what is known of their visual system.

The examples used until this point are from dark-adapted eyes, and $k$, the peak absorption coefficient in Eq. [2], remained constant. In these examples $\lambda_{\max }$, the wavelength of peak absorbance of each photoreceptor, and $A i / A$, the relative area or frequency in cross section of each photoreceptor, were allowed to vary for optimization. However, relative opsin gene expression levels can vary over short time scales (Fuller \& Claricoates, 2011), or can change depending on light environment (Fuller, Noa \& Strellner, 2010). Therefore, an additional goal of the modeling framework presented here was to use overall sensitivity to map relative opsin expression levels to visual pigment concentration in an organism with well-characterized photoreceptor classes, by allowing $k$ to vary. The bluefin killifish, Lucania goodei, was used as two populations found in spring (broad wavelength) and swamp (red-shifted) light environments have been shown to differ in relative opsin expression level for multiple cone photoreceptor classes. The first two rows of Table 4 show the known values of $\lambda_{\max }$, and $A i / A$ which were entered as constants into this framework, and the final two rows show the expression level of each opsin in proportion to all other opsins which were measured in a real-time PCR study (Fuller et al., 2004).

The alternative hypotheses in this example pertained to the number of photoreceptors that had visual pigments with absorption coefficients $k$ greater than $0.001 / \mu \mathrm{m}$. The three best models for the spring population are all well supported by the data (evidence ratio $<2.0$ ), indicating that the framework presented here will select the presence of photoreceptors with 3 or 4 visual pigments in meaningful concentrations; the model with 3 visual pigments is supported for the swamp population (Table5). Though killifish are known to have at least five main spectral cone photoreceptor classes, relative expression levels of class SWS2A reported to date for this species are not found at meaningful expression levels (Table 4) (Fuller et al., 2004). The relative frequency of UV photoreceptors (which express opsin SWS) for swamp populations is less than 0.01 (Table 4), indicating 3 visual pigments are likely the main contributors to overall sensitivity. The best SSH models and transmittance through the lens and ellipsosomes are shown in Figure 2. 
330 The optimized values of $k$ for each visual pigment were also informative. Though they tended to

331 individually be less than values typically found in vertebrate photoreceptors, the sum of these 332 ranges from 0.0163 in the best $4 \mathrm{SSH}$ model, to $\sim 0.0455$ in one of 3 GFKRD models. These are

333 all within the range of $k$ typically found in vertebrate photoreceptors (Cronin et al., 2014). These 334 values are informative for two reasons: first, they mean that there are most likely physiological

335 limits to visual pigment concentrations because they are near saturation in photoreceptors, and 336 second, when modeling $k$ it is assumed to be at the peak wavelength of each visual pigment, 337 which is not possible at all wavelengths, which has been addressed by (Warrant \& Nilsson, 338 1998). Further, when $k$ is compared to the sum of all $k$ values in Figure 3, it becomes apparent 339 that the main opsin expression results have been reproduced by these optimized models. This 340 indicates that future opsin expression studies, which are often difficult to place in context of 341 either overall sensitivity or behavior (Fuller \& Noa, 2010) could use the framework suggested 342 here, and models of overall sensitivity inferred from extracellular ERGS.

343 Currently, empirical studies which identify the spectral properties of individual 344 photoreceptor cells or visual pigments are difficult to place in the larger context of the visual 345 system if all the organism's spectral classes are not identified. The framework I have presented 346 here can be informative for future opsin expression studies and for objectively guiding extracellular or intracellular electroretinography.

\section{Acknowledgements}

350 I thank Justin Marshall and one anonymous reviewer for their reviews of a previous version of this manuscript, as well as the editor, Magnus Johnson. Thanks to Ronald Rutowski and Jonathan Cohen for support throughout the course of this research.

354 The author declares none.

\section{Competing Interests}

357 Supported by the National Science Foundation Graduate Research Fellowship under Grant 358 No.DGE-0802261

\section{REFERENCES}


361

Akaike H. 1974. A new look at the statistical model identification. IEEE transactions on automatic control 19:716-723.

Arendt D., Tessmar-Raible K., Snyman H., Dorresteijn AW., Wittbrodt J. 2004. Ciliary photoreceptors with a vertebrate-type opsin in an invertebrate brain. Science 306:869-871.

Arikawa K. 2003. Spectral organization of the eye of a butterfly, Papilio. Journal of Comparative Physiology A 189:791-800.

Arikawa K., Inokuma K., Eguchi E. 1987. Pentachromatic visual system in a butterfly. Naturwissenschaften 74:297-298.

Arikawa K., Stavenga DG. 1997. Random array of colour filters in the eyes of butterflies. Journal of Experimental Biology 200:2501-2506.

Arnold TW. 2010. Uninformative parameters and model selection using Akaike's Information Criterion. The Journal of Wildlife Management 74:1175-1178.

Beckmann H., Hering L., Henze MJ., Kelber A., Stevenson PA., Mayer G. 2015. Spectral sensitivity in Onychophora (velvet worms) revealed by electroretinograms, phototactic behaviour and opsin gene expression. Journal of Experimental Biology 218:915-922.

Bowmaker JK. 1999. Molecular biology of photoreceptor spectral sensitivity. In: Adaptive Mechanisms in the Ecology of Vision. Dordrecht: Kluwer Academic Publishers, 439-464.

Bowmaker JK., Dartnall HJ. 1980. Visual pigments of rods and cones in a human retina. The Journal of Physiology 298:501-511.

Bruno M., Barnes S., Goldsmith TH. 1977. The visual pigment and visual cycle of the lobster, Homarus. Journal of Comparative Physiology A 120:123-142.

Burnham KP., Anderson DR. 2002. Model Selection and Multimodel Inference: a Practical Information-Theoretic Approach. New York, NY: Springer Science \& Business Media.

Cronin TW., Johnsen S., Marshall NJ., Warrant EJ. 2014. Visual Ecology. Princeton University Press.

Dartnall HJA. 1953. The interpretation of spectral sensitivity curves. British Medical Bulletin 9:24-30.

Fedorov S. 2013.GetData Graph Digitizer. Available at http://getdata-graph-digitizer.com Flamarique IN., Harosi F. 2000. Photoreceptors, visual pigments, and ellipsosomes in the killifish, Fundulus heteroclitus: A microspectrophotometric and histological study. Visual Neuroscience 17:403-420. 
392 Fuller RC., Carleton KL., Fadool JM., Spady TC., Travis J. 2004. Population variation in opsin

393

394

395

396

397

398

399

400

401

402

403

404

405

406

407

408

409

410

411

412

413

414

415

416

417

418

419

420

421

422 expression in the bluefin killifish, Lucania goodei: a real-time PCR study. Journal of Comparative Physiology A 190:147-154.

Fuller RC., Claricoates KM. 2011. Rapid light-induced shifts in opsin expression: finding new opsins, discerning mechanisms of change, and implications for visual sensitivity. Molecular Ecology 20:3321-35.

Fuller RC., Fleishman LJ., Leal M., Travis J., Loew E. 2003. Intraspecific variation in retinal cone distribution in the bluefin killifish, Lucania goodei. Journal of Comparative Physiology A 189:609-616.

Fuller RC., Noa LA. 2010. Female mating preferences, lighting environment, and a test of the sensory bias hypothesis in the bluefin killifish. Animal Behaviour 80:23-35.

Fuller RC., Noa L a., Strellner RS. 2010. Teasing apart the many effects of lighting environment on opsin expression and foraging preference in bluefin killifish. The American Naturalist $176: 1-13$.

Goldsmith TH. 1986. Interpreting trans-retinal recordings of spectral sensitivity. Journal of Comparative Physiology A 159:481-487.

Govardovskii VI., Fyhrquist N., Reuter T., Kuzmin DG., Donner K. 2000. In search of the visual pigment template. Visual Neuroscience 17:509-528.

Haider NB., Jacobson SG., Cideciyan A V., Swiderski R., Streb LM., Searby C., Beck G., Hockey R., Hanna DB., Gorman S., Duhl D., Carmi R., Bennett J., Weleber RG., Fishman GA., Wright AF., Stone EM., Sheffield VC. 2000. Mutation of a nuclear receptor gene, NR2E3, causes enhanced S cone syndrome, a disorder of retinal cell fate. Nature Genetics $24: 127-131$.

Hood DC., Cideciyan A V., Roman AJ., Jacobson SG. 1995. Enhanced S cone syndrome: Evidence for an abnormally large number of S cones. Vision Research 35:1473-1481.

Horodysky AZ., Brill RW., Warrant EJ., Musick JA., Latour RJ. 2008. Comparative visual function in five sciaenid fishes inhabiting Chesapeake Bay. Journal of Experimental Biology 211:3601-3612.

Horodysky AZ., Brill RW., Warrant EJ., Musick JA., Latour RJ. 2010. Comparative visual function in four piscivorous fishes inhabiting Chesapeake Bay. Journal of Experimental Biology 213:1751-1761. 
423

424

425

426

427

428

429

430

431

432

433

434

435

436

437

438

439

440

441

442

443

444

445

446

447

448

449

450

451

452

453

Jacobson SG., Marmor MF., Kemp CM., Knighton RW. 1990. SWS (blue) cone hypersensitivity in a newly identified retinal degeneration. Investigative Ophthalmology \& Visual Science 31:827-838.

Kelber A., Henze MJ. 2013. Colour vision: parallel pathways intersect in Drosophila. Current Biology 23:R1043-R1045.

Kelber A., Osorio D. 2010. From spectral information to animal colour vision: experiments and concepts. Proceedings of the Royal Society B: Biological Sciences 277:1617-25.

Koshitaka H., Kinoshita M., Vorobyev M., Arikawa K. 2008. Tetrachromacy in a butterfly that has eight varieties of spectral receptors. Proceedings of the Royal Society B: Biological Sciences 275:947-54.

Lisney TJ., Studd E., Hawryshyn CW. 2010. Electrophysiological assessment of spectral sensitivity in adult Nile tilapia Oreochromis niloticus: evidence for violet sensitivity. Journal of Experimental Biology 213:1453-1463.

Martin JW. 1992. Branchiopoda. In: Harrison FW, Humes AG eds. Microscopic Anatomy of Invertebrates. New York: Wiley-Liss, Inc., 25-224.

Moldstad AJ. 2008. Development of vision and the effect of spectral environment on the cone photoreceptor mosaic of the bluefin killifish. Master's Thesis, Florida State University.

Porter ML., Blasic JR., Bok MJ., Cameron EG., Pringle T., Cronin TW., Robinson PR. 2012. Shedding new light on opsin evolution. Proceedings of the Royal Society B: Biological Sciences 279:3-14.

Porter ML., Cronin TW., McClellan D a., Crandall K a. 2007. Molecular characterization of crustacean visual pigments and the evolution of pancrustacean opsins. Molecular Biology and Evolution 24:253-68.

Posada D., Buckley TR. 2004. Model selection and model averaging in phylogenetics: advantages of Akaike Information Criterion and Bayesian approaches over likelihood ratio tests. Systematic Biology 53:793-808.

Smith KC., Macagno ER. 1990. UV photoreceptors in the compound eye of Daphnia magna (Crustacea, Branchiopoda). A fourth spectral class in single ommatidia. Journal of Comparative Physiology A 166:597-606.

Snyder AW., Menzel R., Laughlin S. 1973. Structure and function of the fused rhabdom. Journal of Comparative Physiology A 87:99-135. 
454 Stavenga DG. 2010. On visual pigment templates and the spectral shape of invertebrate

455

456

457

458

459

460

461

462

463

464

465

466

467

468

469

470

471 rhodopsins and metarhodopsins. Journal of Comparative Physiology A 196:869-878.

Stavenga DG., Arikawa K. 2011. Photoreceptor spectral sensitivities of the Small White butterfly Pieris rapae crucivora interpreted with optical modeling. Journal of Comparative Physiology A 197:373-385.

Stavenga DG., Smits RP., Hoenders BJ. 1993. Simple exponential functions describing the absorbance bands of visual pigment spectra. Vision Research 33:1011-7.

Symonds MRE., Moussalli A. 2011. A brief guide to model selection, multimodel inference and model averaging in behavioural ecology using Akaike's information criterion. Behavioral Ecology and Sociobiology 65:13-21.

Wakakuwa M., Stavenga DG., Arikawa K. 2007. Spectral organization of ommatidia in flowervisiting insects. Photochemistry and Photobiology 83:27-34.

Warrant EJ., Nilsson D-E. 1998. Absorption of white light in photoreceptors. Vision Research 38:195-207.

Wyszecki G., Stiles WS. 1982. Color Science. Wiley New York.

Wyszecki G., Stiles WS. 2000. Color Science: Concepts and Methods, Quantitative Data and Formulae. Wiley-Interscience, New York.

Figure legends

Figure 1. Photoreceptor absorptance models (curves) based on known photoreceptor lengths and vertical tiering, fit to relative spectral sensitivity data extracted from published sources (data points). Models were selected using Akaike's Information Criterion corrected for small sample sizes $\left(\mathrm{AIC}_{\mathrm{c}}\right)$ with the best three models shown in Tables 1 and 2 , and all models in Tables S1-S2. (A) Velvet worm Principapillatus hitoyensis sensitivity, known to be represented by a single spectral opsin class expressed in its photoreceptors (Beckmann et al., 2015). (B and C) Normal and Enhanced S cone Human scotopic sensitivities, known for normal humans to be represented by S-class cone and rod photoreceptor sensitivities, and with a higher frequency of $\mathrm{S}$ cones in patients that have Enhanced S Cone syndrome (Jacobson et al., 1990; Hood et al., 1995; Haider et al., 2000). Absorptance models for humans are corrected for transmittance through the lens and a distal macula layer which protects the retina, but which does not contribute to spectral sensitivity (gray lines) (Wyszecki \& Stiles, 2000). D) Daphnia magna sensitivity, known to be 
represented by four spectral photoreceptor classes with a distal UV receptor (Smith \& Macagno, 1990). (E and F) Papilio xuthus sensitivity, averaged from extracellular recordings from multiple positions in the compound eye, known to be represented by at least five main spectral photoreceptor classes (Arikawa, Inokuma \& Eguchi, 1987). (E) Absorptance models (dashed lines) illustrate poor results with this technique because of model-oversimplification explained in text. (F) Absorbance (given by Eq.1) at a cross-section approximately two thirds from the distal tip of the rhabdom of an ommatidium selects 5 spectral photoreceptor classes, with deviations of each spectral class explained further in the text due to specialized filtering pigments.

Figure 2. Absorption coefficient models based on known relative opsin expression levels from two populations for the killifish, Lucania goodei. Models were fit to relative spectral sensitivity data extracted from published sources (data points). Models were selected using Akaike's Information Criterion corrected for small sample sizes $\left(\mathrm{AIC}_{\mathrm{c}}\right)$ with the best three models shown in Tables 1 and 2, and all models in Tables S3. $\lambda_{\max }$ and $A i / A$ were held constant and not included as parameters.

Figure 3. Absorption coefficient values from Table 4 for comparison to relative opsin expression levels from (Fuller et al., 2004). Opsin expression was quantified relative to the total opsin expression level. 
Table 1. Absorptance model comparisons for Principapillatus hitoyensis and Homo sapiens using maximum likelihood and Akaike's Information Criterion corrected for small sample sizes (AICc). Photoreceptor arrays were modeled for each species and condition using parameters from Equations 1 and 2 (Materials and Methods). $\mathrm{A}_{\mathrm{i}} / \mathrm{A}$, relative area of photoreceptor in cross-section. SSH, rhodopsin visual pigment template (Stavenga, Smits \& Hoenders, 1993). GFRKD, rhodopsin visual pigment template (Govardovskii et al., 2000). Three best supported models are displayed here for each species or condition. All model comparisons considered are included in Table S1. Evidence ratios were calculated relative to the best model for each species or condition. Models with ambiguous $w \mathrm{AIC}_{\mathrm{c}}($ evidence ratio $<2.0)$ are indicated by $\left({ }^{\mathrm{a}}\right)$. Models with low support relative to the best model (evidence ratio $>2.0$ ) are indicated by $\left({ }^{b}\right)$.

\begin{tabular}{|c|c|c|c|c|c|c|c|c|c|}
\hline $\begin{array}{l}\text { Species or } \\
\text { Condition }\end{array}$ & $\begin{array}{c}\text { (Reference) } \\
\text { Model }\end{array}$ & $\begin{array}{l}\lambda \max _{1} \\
\left(\mathrm{~A}_{1} / \mathrm{A}\right)\end{array}$ & $\begin{array}{l}\lambda \max _{2} \\
\left(\mathbf{A}_{2} / \mathrm{A}\right)\end{array}$ & $\begin{array}{l}\lambda \max _{3} \\
\left(\mathrm{~A}_{3} / \mathrm{A}\right)\end{array}$ & $\begin{array}{l}\lambda \max _{4} \\
\left(\mathbf{A}_{4} / \mathbf{A}\right)\end{array}$ & $\mathrm{AIC}_{\mathrm{c}}$ & $\Delta \mathrm{AIC}_{\mathrm{c}}$ & $w \mathrm{AIC}_{\mathrm{c}}$ & $\begin{array}{c}\text { Evidence } \\
\text { Ratio }\end{array}$ \\
\hline \multirow[t]{4}{*}{ P.hitoyensis } & $\begin{array}{l}\text { (Beckmann } \\
\text { et al., 2015) }\end{array}$ & 484 & - & - & - & - & - & - & - \\
\hline & 1,GFKRD & $\begin{array}{c}481 \\
(1.0)\end{array}$ & - & - & - & 55.8 & 0 & 0.508 & - \\
\hline & $1, \mathrm{SSH}^{\mathrm{a}}$ & $\begin{array}{l}481 \\
(1.0)\end{array}$ & - & - & - & 54.9 & 0.863 & 0.330 & 1.54 \\
\hline & $2, \mathrm{GFKRD}^{\mathrm{b}}$ & $\begin{array}{c}481 \\
(0.70)\end{array}$ & $\begin{array}{c}481 \\
(0.30)\end{array}$ & - & - & 53.2 & 2.54 & 0.143 & 3.56 \\
\hline \multirow[t]{4}{*}{$\begin{array}{l}\text { Normal } \\
\text { Human } \\
\text { (scotopic) }\end{array}$} & $\begin{array}{l}\text { (Wyszecki } \\
\text { \& Stiles, } \\
\text { 2000) }\end{array}$ & 420 & 497 & - & - & - & - & - & - \\
\hline & 2,SSH & $\begin{array}{c}421 \\
(0.16)\end{array}$ & $\begin{array}{c}495 \\
(0.85)\end{array}$ & - & - & 91.3 & 0 & 0.500 & - \\
\hline & 2,GFKRD ${ }^{\mathrm{a}}$ & $\begin{array}{c}419 \\
(0.17)\end{array}$ & $\begin{array}{c}495 \\
(0.83)\end{array}$ & - & - & 91.1 & 0.176 & 0.458 & 1.09 \\
\hline & $3, \mathrm{SSH}^{\mathrm{b}}$ & $\begin{array}{c}407 \\
(0.11)\end{array}$ & $\begin{array}{c}493 \\
(0.45)\end{array}$ & $\begin{array}{c}493 \\
(0.45)\end{array}$ & - & 85.1 & 6.24 & 0.02 & 22.6 \\
\hline \multirow{4}{*}{$\begin{array}{l}\text { Enchanced } \\
\text { S-cone } \\
\text { Human } \\
\text { (scotopic) }\end{array}$} & $\begin{array}{c}\text { (Jacobson et } \\
\text { al., 1990) }\end{array}$ & 420 & 497 & - & - & - & - & - & - \\
\hline & $2, \mathrm{SSH}$ & $\begin{array}{c}429 \\
(0.76)\end{array}$ & $\begin{array}{c}506 \\
(0.24)\end{array}$ & - & - & 65.6 & 0 & 0.587 & - \\
\hline & $2, \mathrm{GFKRD}^{\mathrm{a}}$ & $\begin{array}{c}429 \\
(0.75)\end{array}$ & $\begin{array}{c}506 \\
(0.25)\end{array}$ & - & - & 64.0 & 1.62 & 0.261 & 2.25 \\
\hline & $3, \mathrm{GFKRD}^{\mathrm{b}}$ & $\begin{array}{c}375 \\
(0.27)\end{array}$ & $\begin{array}{c}432 \\
(0.54)\end{array}$ & $\begin{array}{c}507 \\
(0.20)\end{array}$ & - & 62.0 & 3.79 & 0.088 & 6.65 \\
\hline
\end{tabular}


Table 2. Absorptance model comparisons for Daphnia magna and Papilio xuthus using maximum likelihood and Akaike's Information Criterion corrected for small sample sizes $\left(\mathbf{A I C}_{\mathbf{c}}\right)$. Tiered photoreceptor arrays were modeled for each species and condition using parameters from Equations 1 and 2 (Materials and Methods). $\mathrm{A}_{\mathrm{i}} / \mathrm{A}$, relative area of photoreceptor in cross-section. SSH, rhodopsin visual pigment template (Stavenga, Smits \& Hoenders, 1993). GFRKD, rhodopsin visual pigment template (Govardovskii et al., 2000). Three best supported models are displayed here for each species or condition. All model comparisons considered are included in Table S2. Evidence ratios were calculated relative to the best model for each species or condition. Models with ambiguous $w \mathrm{AIC}_{\mathrm{c}}$ (evidence ratio <2.0) are indicated by ( ${ }^{\mathrm{a}}$ ). Models with low support relative to the best model (evidence ratio $>2.0$ ) are indicated by $\left({ }^{b}\right)$.

\begin{tabular}{|c|c|c|c|c|c|c|c|c|c|c|}
\hline $\begin{array}{l}\text { Species or } \\
\text { Condition }\end{array}$ & $\begin{array}{c}\text { (Reference) } \\
\text { Model }\end{array}$ & $\begin{array}{l}\lambda \max _{1} \\
\left(A_{1} / A\right)\end{array}$ & $\begin{array}{l}\lambda \max _{2} \\
\left(\mathrm{~A}_{2} / \mathrm{A}\right)\end{array}$ & $\begin{array}{l}\lambda \max _{3} \\
\left(\mathbf{A}_{3} / \mathbf{A}\right)\end{array}$ & $\begin{array}{l}\lambda \max _{4} \\
\left(\mathbf{A}_{4} / \mathbf{A}\right)\end{array}$ & $\begin{array}{l}\lambda \max _{5} \\
\left(\mathbf{A}_{5} / \mathbf{A}\right)\end{array}$ & $\mathrm{AIC}_{\mathrm{c}}$ & $\Delta \mathrm{AIC}_{\mathrm{c}}$ & $w \mathrm{AIC}_{\mathrm{c}}$ & $\begin{array}{c}\text { Evidence } \\
\text { Ratio }\end{array}$ \\
\hline \multirow[t]{4}{*}{$\begin{array}{c}\text { D. magna } \\
\text { (Tiered } \\
\text { absorptance) }\end{array}$} & $\begin{array}{c}\text { (Smith \& } \\
\text { Macagno, } \\
\text { 1990) }\end{array}$ & 356 & 440 & 521 & 592 & - & - & - & - & - \\
\hline & $4, \mathrm{SSH}$ & $\begin{array}{c}362 \\
(0.52)\end{array}$ & $\begin{array}{c}442 \\
(0.21)\end{array}$ & $\begin{array}{c}518 \\
(0.12)\end{array}$ & $\begin{array}{c}587 \\
(0.15)\end{array}$ & - & 46.2 & 0 & 0.979 & - \\
\hline & $3, \mathrm{SSH}^{\mathrm{b}}$ & $\begin{array}{c}367 \\
(0.50)\end{array}$ & $\begin{array}{c}455 \\
(0.22)\end{array}$ & $\begin{array}{c}560 \\
(0.28)\end{array}$ & - & - & 38.3 & 7.96 & 0.018 & 53.64 \\
\hline & 4, GFKRD $^{\mathrm{b}}$ & $\begin{array}{c}364 \\
(0.50)\end{array}$ & $\begin{array}{c}437 \\
(0.21)\end{array}$ & $\begin{array}{c}508 \\
(0.12)\end{array}$ & $\begin{array}{c}582 \\
(0.17)\end{array}$ & - & 33.3 & 12.97 & $<0.01$ & 656 \\
\hline \multirow[t]{4}{*}{$\begin{array}{c}\text { P. xuthus } \\
\text { (Tiered } \\
\text { absorptance) }\end{array}$} & $\begin{array}{l}\text { (Arikawa, } \\
\text { Inokuma \& } \\
\text { Eguchi, } \\
\text { 1987) }\end{array}$ & 360 & $\begin{array}{c}390 / \\
400\end{array}$ & 460 & 520 & 600 & - & - & - & - \\
\hline & $2, \mathrm{SSH}$ & $\begin{array}{c}429 \\
(0.48)\end{array}$ & $\begin{array}{c}529 \\
(0.52)\end{array}$ & - & - & - & 34.9 & 0 & 0.726 & - \\
\hline & $3, \mathrm{SSH}^{\mathrm{b}}$ & $\begin{array}{c}429 \\
(0.56)\end{array}$ & $\begin{array}{c}505 \\
(0.23)\end{array}$ & $\begin{array}{c}559 \\
(0.21)\end{array}$ & - & - & 31.4 & 3.477 & 0.128 & 5.69 \\
\hline & $2, \mathrm{GFKRD}^{\mathrm{b}}$ & $\begin{array}{c}422 \\
(0.49)\end{array}$ & $\begin{array}{c}529 \\
(0.51)\end{array}$ & - & - & - & 30.5 & 4.389 & 0.081 & 8.98 \\
\hline \multirow[t]{4}{*}{$\begin{array}{c}\text { P. xuthus } \\
\text { (Absorbance) }\end{array}$} & $\begin{array}{l}\text { (Arikawa, } \\
\text { Inokuma \& } \\
\text { Eguchi, } \\
\text { 1987) }\end{array}$ & 360 & $\begin{array}{c}390 / \\
400\end{array}$ & 460 & 520 & 600 & - & - & - & - \\
\hline & 5, GFKRD & $\begin{array}{c}346 \\
(0.10)\end{array}$ & $\begin{array}{c}381 \\
(0.25)\end{array}$ & $\begin{array}{c}457 \\
(0.32)\end{array}$ & $\begin{array}{c}529 \\
(0.20)\end{array}$ & $\begin{array}{c}586 \\
(0.12)\end{array}$ & 50.4 & 0 & 0.653 & - \\
\hline & $3, \mathrm{SSH}^{\mathrm{b}}$ & $\begin{array}{c}371 \\
(0.35)\end{array}$ & $\begin{array}{c}463 \\
(0.37)\end{array}$ & $\begin{array}{c}557 \\
(0.28)\end{array}$ & - & - & 47.8 & 2.63 & 0.176 & 3.71 \\
\hline & 4, GFKRD $^{\mathrm{b}}$ & $\begin{array}{c}348 \\
(0.13)\end{array}$ & $\begin{array}{c}385 \\
(0.26)\end{array}$ & $\begin{array}{c}465 \\
(0.36)\end{array}$ & $\begin{array}{c}559 \\
(0.25)\end{array}$ & - & 46.6 & 3.83 & 0.096 & 6.77 \\
\hline
\end{tabular}


Table 3. AIC inferences compared to traditional hypothesis testing which uses an $\boldsymbol{F}$-test to distinguish between two best models of similar fit. The best model and the closest model with a different number of photoreceptor spectral classes according to AIC are displayed in this order for each species or condition. An F-test typically used for comparing non-linear regression models with similar fits was used here to compare two models with lowest residual sum of squares. In cases were $p<0.05$ the model with more parameters is accepted. Examples which deviated from AIC results are shown with an asterisk (*). This comparison indicates that AIC provides a similar framework to nonlinear regression to compare multiple models and can generally eliminate unneeded parameters (in this table, photoreceptor classes and cross-sectional area).

\begin{tabular}{|c|c|c|c|c|c|c|}
\hline $\begin{array}{l}\text { Species or } \\
\text { Condition }\end{array}$ & Model & $\begin{array}{c}\text { Residual } \\
\text { Sum of } \\
\text { Squares } \\
\text { (RSS) }\end{array}$ & $\begin{array}{c}F \text {-test } \\
\text { comparing } \\
\text { two models } \\
\text { with best fit }\end{array}$ & $\begin{array}{c}p \text { value } \\
\text { from } \\
F \text {-test }\end{array}$ & $\begin{array}{c}\text { Number of } \\
\text { parameters } \\
(K)\end{array}$ & $\begin{array}{c}\text { Evidence } \\
\text { Ratio }\end{array}$ \\
\hline \multirow[t]{2}{*}{ P.hitoyensis } & 1,GFKRD & 0.031 & 1.90 & 0.13 & 3 & - \\
\hline & 2, GFKRD & 0.024 & - & - & 5 & 3.56 \\
\hline \multirow{2}{*}{$\begin{array}{l}\text { Normal Human } \\
\text { (scotopic) }\end{array}$} & $2, \mathrm{SSH}$ & 0.003 & 2.75 & $0.05^{*}$ & 5 & - \\
\hline & $3, \mathrm{SSH}$ & 0.002 & - & - & 7 & 22.6 \\
\hline Enhanced S-cone & $2, \mathrm{SSH}$ & 0.012 & 2.75 & $0.05^{*}$ & 5 & - \\
\hline \multicolumn{7}{|l|}{ Human (scotopic) } \\
\hline & 3, GFKRD & 0.008 & - & - & 7 & 6.65 \\
\hline \multirow[t]{2}{*}{ D. magna } & 4,SSH & 0.009 & 11 & $<0.001$ & 9 & - \\
\hline & $3, \mathrm{SSH}$ & 0.031 & - & - & 7 & 53.64 \\
\hline \multirow{2}{*}{$\begin{array}{l}\text { P. xuthus (Tiered } \\
\text { absorptance) }\end{array}$} & $2, \mathrm{SSH}$ & 0.100 & 2.05 & 0.10 & 5 & - \\
\hline & 3,SSH & 0.076 & - & - & 7 & 5.69 \\
\hline \multirow{2}{*}{$\begin{array}{l}\text { P. xuthus } \\
\text { (Absorbance) }\end{array}$} & 5, GFKRD & 0.006 & 10.5 & $<0.001$ & 11 & - \\
\hline & $3, \mathrm{SSH}$ & 0.034 & - & - & 7 & 3.71 \\
\hline
\end{tabular}


Table 4 Photoreceptor parameters and reported relative opsin expression values for two populations of $\boldsymbol{L}$ goodei used in modeling absorption coefficient $\boldsymbol{k}$ for known opsin-based spectral photoreceptor classes. Values for $\lambda \max$ and cone frequencies $\left(\mathrm{A}_{\mathrm{i}} / \mathrm{A}\right)$ were identified using microspectrophotometry (Fuller et al., 2003). These values were incorporated as constants into model optimization of absorption coefficients below. Relative opsin expression (exp) is in comparison to the sum of all opsins expression is reported from (Fuller et al., 2004) Relative expression levels should be compared to Table 5 normalized absorption coefficients.

\begin{tabular}{|c|c|c|c|c|c|c|c|c|c|c|}
\hline $\begin{array}{l}\text { Species and } \\
\text { population }\end{array}$ & $\begin{array}{l}\lambda \max _{1} \\
\left(\mathbf{A}_{1} / \mathbf{A}\right)\end{array}$ & $\begin{array}{l}\operatorname{opsin}_{1} \\
(\exp )\end{array}$ & $\begin{array}{l}\lambda \max _{2} \\
\left(\mathrm{~A}_{2} / \mathrm{A}\right)\end{array}$ & $\begin{array}{c}\text { opsin }_{2} \\
(\exp ) \\
\end{array}$ & $\begin{array}{l}\lambda \max _{3} \\
\left(A_{3} / A\right)\end{array}$ & $\begin{array}{c}\text { opsin }_{3} \\
(\exp ) \\
\end{array}$ & $\begin{array}{l}\lambda \max _{4} \\
\left(\mathrm{~A}_{4} / \mathrm{A}\right) \\
\end{array}$ & $\begin{array}{c}\operatorname{opsin}_{4} \\
(\exp ) \\
\end{array}$ & $\begin{array}{l}\lambda \max _{5} \\
\left(\mathrm{~A}_{5} / \mathrm{A}\right) \\
\end{array}$ & $\begin{array}{c}\operatorname{opsin}_{5} \\
(\exp ) \\
\end{array}$ \\
\hline $\begin{array}{l}\text { L. goodei } \\
\text { Spring } \\
\text { population }\end{array}$ & $\begin{array}{c}359 \\
(0.08)\end{array}$ & $\begin{array}{l}\text { SWS1 } \\
(0.21)\end{array}$ & $\begin{array}{c}405 \\
(0.31)\end{array}$ & $\begin{array}{c}\text { SWS2B } \\
(0.26)\end{array}$ & $\begin{array}{c}454 \\
(0.16)\end{array}$ & $\begin{array}{c}\text { SWS2A } \\
(<0.01)\end{array}$ & $\begin{array}{c}538 \\
(0.25)\end{array}$ & $\begin{array}{l}\text { RH2-1 } \\
(0.27)\end{array}$ & $\begin{array}{c}572 \\
(0.25)\end{array}$ & $\begin{array}{l}\text { LWS } \\
(0.25)\end{array}$ \\
\hline $\begin{array}{l}\text { L. goodei } \\
\text { Swamp } \\
\text { population }\end{array}$ & $\begin{array}{c}359 \\
(<0.01)\end{array}$ & $\begin{array}{l}\text { SWS1 } \\
(0.11)\end{array}$ & $\begin{array}{c}405 \\
(0.16)\end{array}$ & $\begin{array}{c}\text { SWS2B } \\
(0.21)\end{array}$ & $\begin{array}{c}456 \\
(0.10)\end{array}$ & $\begin{array}{c}\text { SWS2A } \\
(<0.01)\end{array}$ & $\begin{array}{c}541 \\
(0.32)\end{array}$ & $\begin{array}{l}\text { RH2-1 } \\
(0.33)\end{array}$ & $\begin{array}{c}573 \\
(0.42)\end{array}$ & $\begin{array}{l}\text { LWS } \\
(0.34)\end{array}$ \\
\hline
\end{tabular}


Table 5 Absorptance model comparisons for two populations of $L$ goodei identify differences in absorption coefficient $\boldsymbol{k}$ for known opsin-based spectral photoreceptor classes. Three best supported models are reported for comparison between absorption coefficients $(k)$ normalized by the sum of absorption coefficients $\left(k_{i} / k\right)$. All model comparisons considered are included in Table S3. Evidence ratios were calculated relative to the best model for each species or condition. Models with ambiguous $w \mathrm{AIC}_{\mathrm{c}}$ (evidence ratio $<2.0$ ) are indicated by $\left({ }^{a}\right)$. Models with low support relative to the best model (evidence ratio $>2.0$ ) are indicated by $\left({ }^{b}\right)$.

\begin{tabular}{|c|c|c|c|c|c|c|c|c|c|c|}
\hline $\begin{array}{l}\text { Species } \\
\text { and } \\
\text { population }\end{array}$ & Model & $\begin{array}{c}S W S 1 \\
k_{1} \\
\left(k_{1} / k\right)\end{array}$ & $\begin{array}{c}S W S 2 B \\
k_{2} \\
\left(k_{2} / k\right)\end{array}$ & $\begin{array}{c}S W S 2 A \\
k_{3} \\
\left(k_{3} / k\right)\end{array}$ & $\begin{array}{c}R H 2-1 \\
k_{4} \\
\left(k_{4} / k\right)\end{array}$ & $\begin{array}{c}L W S \\
k_{5} \\
\left(k_{5} / k\right)\end{array}$ & $\mathrm{AIC}_{\mathrm{c}}$ & $\Delta \mathrm{AIC}_{\mathrm{c}}$ & $w \mathrm{AIC}_{\mathrm{c}}$ & $\begin{array}{c}\text { Evidence } \\
\text { Ratio }\end{array}$ \\
\hline \multirow{3}{*}{$\begin{array}{l}\text { L. goodei } \\
\text { Spring } \\
\text { population }\end{array}$} & $3, \mathrm{SSH}^{\mathrm{a}}$ & $\begin{array}{l}- \\
(-)\end{array}$ & $\begin{array}{l}0.0045 \\
(0.40)\end{array}$ & $\begin{array}{l} \\
-\end{array}$ & $\begin{array}{l}0.0042 \\
(0.37)\end{array}$ & $\begin{array}{l}0.0027 \\
(0.24)\end{array}$ & 37.8 & 0 & 0.448 & - \\
\hline & $3, \mathrm{GFKRD}^{\mathrm{a}}$ & $\begin{array}{l}- \\
(-)\end{array}$ & $\begin{array}{l}0.019 \\
(0.42)\end{array}$ & $(-)$ & $\begin{array}{l}0.017 \\
(0.38)\end{array}$ & $\begin{array}{l}0.0095 \\
(0.21)\end{array}$ & 37.0 & 0.819 & 0.298 & 1.51 \\
\hline & $4, \mathrm{SSH}^{\mathrm{a}}$ & $\begin{array}{c}0.0030 \\
(0.18)\end{array}$ & $\begin{array}{l}0.0051 \\
(0.32)\end{array}$ & $(-)$ & $\begin{array}{c}0.0050 \\
(0.31)\end{array}$ & $\begin{array}{c}0.0032 \\
(0.20)\end{array}$ & 36.7 & 1.18 & 0.249 & 1.80 \\
\hline \multirow{3}{*}{$\begin{array}{l}\text { L. goodei } \\
\text { Swamp } \\
\text { population }\end{array}$} & $3, \mathrm{SSH}^{\mathrm{b}}$ & - & $\begin{array}{l}0.0027 \\
(0.28)\end{array}$ & - & $\begin{array}{c}0.0036 \\
(0.38)\end{array}$ & $\begin{array}{c}0.0033 \\
(0.34)\end{array}$ & 37.0 & 0 & 0.945 & - \\
\hline & 3, GFKRD $^{\mathrm{b}}$ & $\begin{array}{l}- \\
(-)\end{array}$ & $\begin{array}{l}0.0077 \\
(0.33)\end{array}$ & $\begin{array}{l}- \\
(-)\end{array}$ & $\begin{array}{c}0.0085 \\
(0.36)\end{array}$ & $\begin{array}{c}0.0074 \\
(0.31)\end{array}$ & 30.2 & 6.833 & 0.031 & 30.46 \\
\hline & $2, \mathrm{SSH}^{\mathrm{b}}$ & $\begin{array}{l}- \\
(-)\end{array}$ & $\begin{array}{l}- \\
(-)\end{array}$ & $\begin{array}{l}- \\
(-)\end{array}$ & $\begin{array}{l}0.011 \\
(0.54)\end{array}$ & $\begin{array}{c}0.0092 \\
(0.46)\end{array}$ & 28.6 & 8.42 & 0.014 & 67.38 \\
\hline
\end{tabular}




\section{Figure 1}
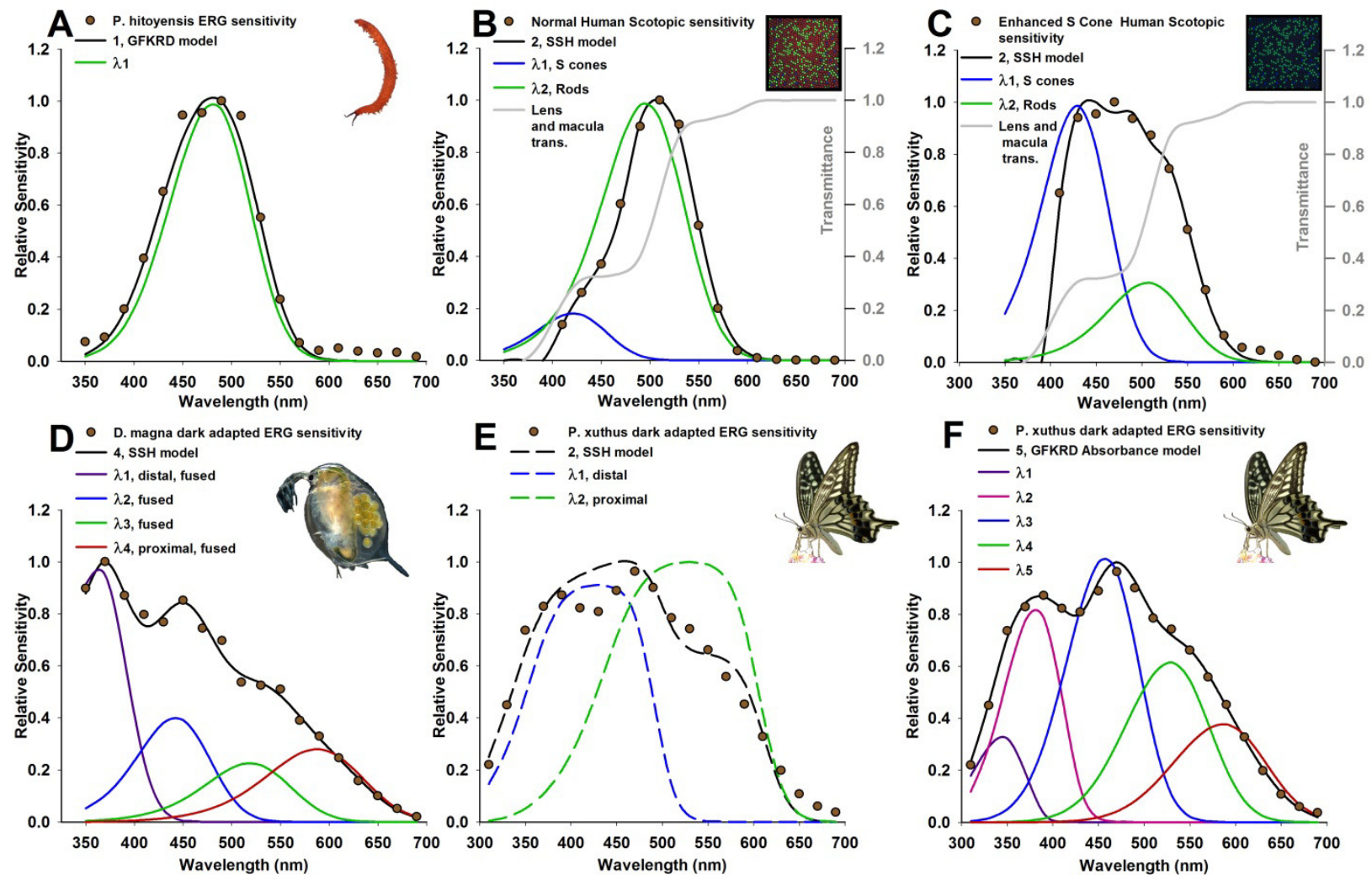
Figure 2
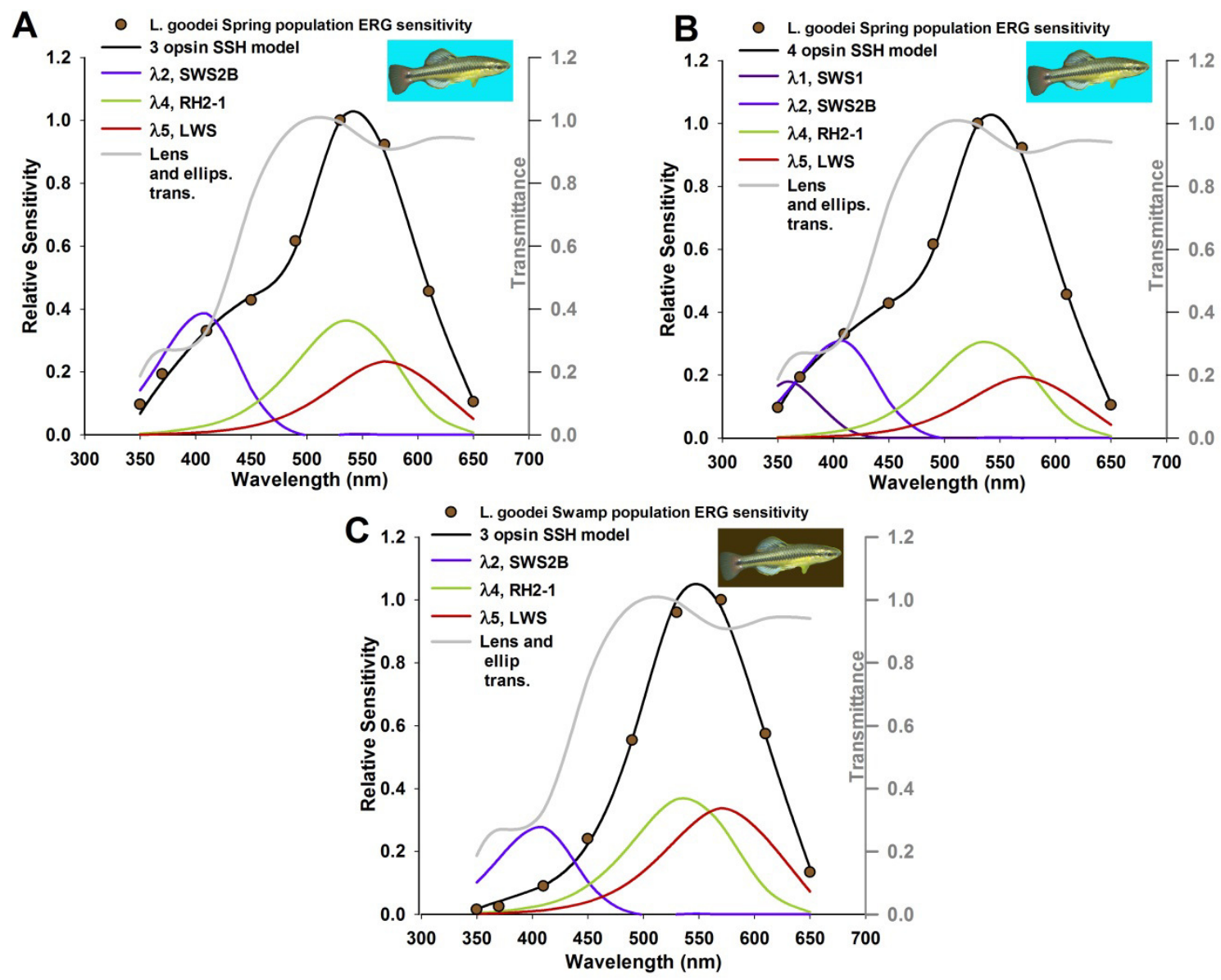
Figure 3

A

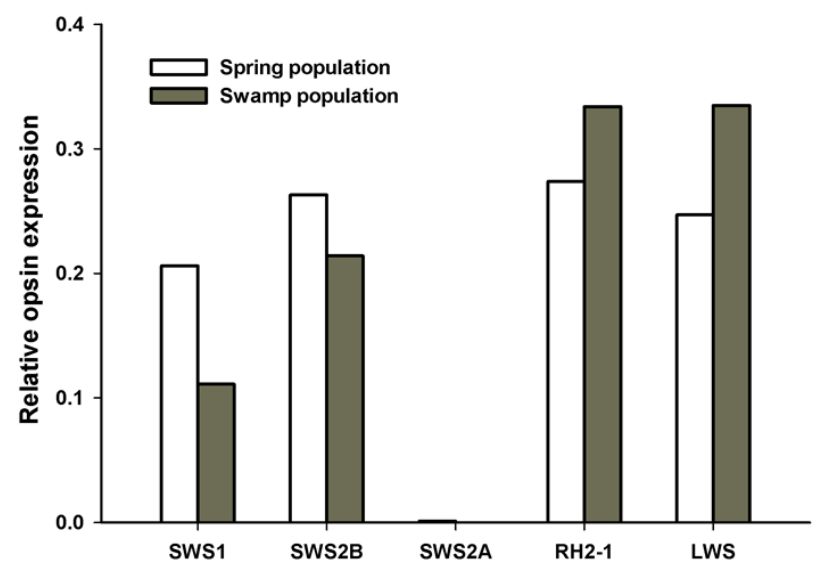

B

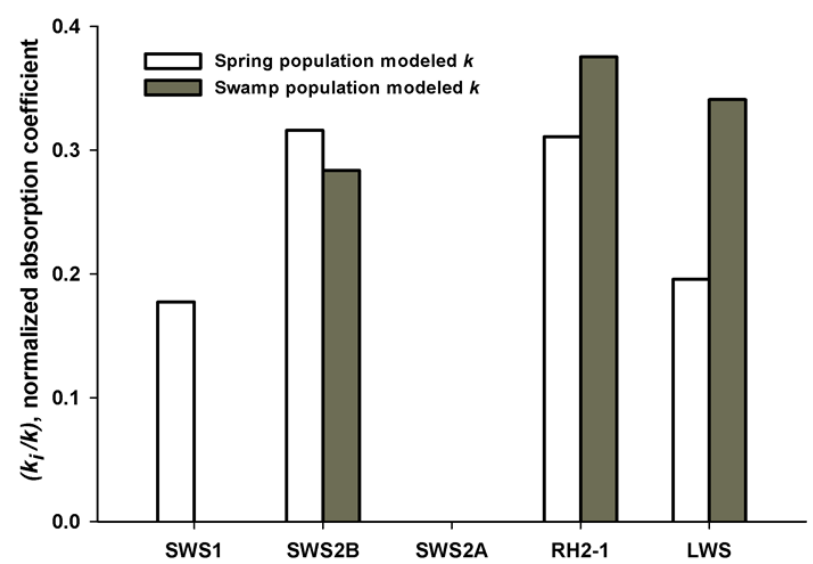

